\title{
Excess lead in the perovskite lattice of PZT thin films made by in-situ reactive sputtering
}

Paul Muralt ${ }^{1}$, Stéphane Hiboux ${ }^{1}$, Claude Mueller ${ }^{1}$, Thomas Maeder ${ }^{1}$, Laurent Sagalowicz ${ }^{1}$, Takeshi Egami ${ }^{2}$ and Nava Setter ${ }^{1}$

1) Ceramics Laboratory, École Polytechnique Fédérale de Lausanne (EPF), CH-1015 Lausanne, Switzerland

2) University of Pennsylvania (UPenn), Philadelphia, USA

Version of record: $\quad$ Integrated Ferroelectrics $36(1-4), 53-62,2001$

http://hdl.handle.net/10.1080/10584580108015527

\begin{abstract}
The incorporation of up to $40 \%$ lead excess into the perovskite lattice of $\mathrm{Pb}(\mathrm{Zr}, \mathrm{Ti}) \mathrm{O}_{3}(\mathrm{PZT})$ has been investigated. Three independent chemical composition analysis methods confirmed the correct determination of the lead excess, present as $\mathrm{Pb}_{2} \mathrm{O}_{3}$. High resolution TEM excludes any second phases and restricts the occurrence of lead excess to the perovskite lattice, suggesting a lead oxide perovskite of the form $\mathrm{Pb}^{2+} \mathrm{Pb}^{4+} \mathrm{O}_{3}$ with a 4-valent ion on the $\mathrm{B}$-site. PZT containing such lead excess is thus a solid solution of $\mathrm{PbZrO}_{3}, \mathrm{PbTiO}_{3}$ and $\mathrm{PbPbO}_{3}$. The measured volume increase of the lattice due to a larger average B-ion matches very well with the calculated behavior based on standard ion radii and the B-ion radius dependence of the unit cell dimensions of PZT crystals. Structure factors as determined from Synchrotron X-ray diffraction are much better compatible with the B- site lead model than with the standard PZT ion lattice.
\end{abstract}

Keywords : Perovskite, Lead Oxide, Thin Films, PZT, sputtering

\section{Introduction}

The fabrication of $\mathrm{Pb}(\mathrm{Zr}, \mathrm{Ti}) \mathrm{O}_{3}$ (or $\mathrm{PZT}$ ) thin films generally requires some excess of lead oxide in order to achieve a homogenous nucleation of the perovskite phase, to overcome inhomogeneities in sol-gel solutions [1], and to obtain a dense film. One uses typically $10 \%$ of lead excess in processes with a post-annealing treatment, be it chemical solution deposition or cold sputtering. It is found that above around $650^{\circ} \mathrm{C}$ the lead excess decreases to about zero $\left(\mathrm{PbTiO}_{3}\right.$, [2]) within a few percent of measurement error. In case of in-situ processes a considerable amount of lead oxide desorbs from the surface. This is accounted for by increasing the lead excess in the vapor (MOCVD [3,4] or the sputter flux. In most cases it is found that the growing perovskite film takes only as much lead as needed to occupy the Asite (see table 1 for notation) of the perovskite lattice, at least in a certain process window.

\begin{tabular}{|l|c|c|c|c|c|}
\hline Ion & $\mathrm{Pb}^{2+}$ & $\mathrm{Ti}^{4+}$ & $\mathrm{Zr}^{4+}$ & $\mathrm{Pb}^{4+}$ & $\mathrm{O}^{2-}$ \\
\hline Position & $\mathrm{A}$ & $\mathrm{B}$ & $\mathrm{B}$ & $\mathrm{B} ?$ & $\mathrm{O}$ \\
\hline Ionic radius (pm) [5] & 163 & 74.5 & 86 & 91.5 & 126 \\
\hline
\end{tabular}

Table 1. Ion positions and ionic radii of paraelectric PZT exhibiting ideal perovskite lattice. 
In a previous work we reported a stabilization of lead oxide at stoichiometric composition in case of $\mathrm{PbTiO}_{3}$ grown at 510 to $600^{\circ} \mathrm{C}$ [6]. Such a low stabilization temperature is thought to be possible due to the plasma impact during sputtering. Lead self-stabilization was found to take place above $600^{\circ} \mathrm{C}$ in case of co-evaporation of $\mathrm{PbO}$ and $\mathrm{TiO}_{2}$ [7]. Later work in $\mathrm{PZT}$ coatings, especially the one on optical fibers $[8,9]$ learned us that there can be a considerable amount of lead excess in the perovskite films, even in the ones showing no sign of a second phase. The problem of lead excess in a perovskite was previously also encountered in reactively, in-situ sputter deposited thin films of $\mathrm{PbSc}_{1 / 2} \mathrm{Ta}_{1 / 2} \mathrm{O}_{3}$ by Whatmore, Huang and Todd [10]. These authors showed convincing results and arguments that the measured lead excess must stay inside the perovskite lattice (general formula $\mathrm{ABO}_{3}$ )and they thus proposed lead to be present also as $\mathrm{Pb}^{4+}$ on the $\mathrm{B}^{-}$site, thus substituting partially $\mathrm{Sc}$ and $\mathrm{Ta}$. The evidence for this to happen was firstly that the interior of the perovskite grains contained more lead than the grain boundaries, and secondly that the thin film lattice constant derived from 8-28 XRD scaled very well with the increased volume expected for $\mathrm{Pb}$ on the B-site. The same authors extended their study to sol-gel processed PZT thin films, however, did not find the same problematics of lead excess in their films. However, we do find it in our films. We think now that lead excess in the perovskite is related to the process conditions prevailing during in-situ sputter deposition.

$\mathrm{Pb}^{+4}$ on the $\mathrm{B}^{-}$site of lead Perovskites would mean to allow a hypothetical $\mathrm{PbPbO}_{3}$ compound in solid perovskite solutions. $\mathrm{Pb}^{4+}$ in the $\mathrm{B}$ sites of the perovskite is known to occur in some materials, such as the oxide conductor $\mathrm{BaPbO}_{3}$, (PDF2 \#48-1794). In fact there are no simples rules forbidding the existence of lead on the B-site. The tolerance factor for perovskite structures $t=2^{0.5} \cdot\left(r_{\mathrm{A}}+r_{\mathrm{O}}\right) /\left(r_{\mathrm{B}}+r_{\mathrm{O}}\right)$ is obtained as $1.02,0.96$ and 0.94 for $\mathrm{B}=\mathrm{Ti}^{4+}$, $\mathrm{Zr}^{4+}$ and $\mathrm{Pb}^{4+}$, respectively. The value for lead is not far away from the one of $\mathrm{Zr}$ and anyway well inside the tolerance interval of $0.8<t<1.1$ [11]. No additional anisotropy of chemical bonds should be introduced by $\mathrm{Pb}^{4+}$, as it possesses filled shells only $\left((\mathrm{Xe}) 4 \mathrm{f}^{14} 5 \mathrm{~d}^{10}\right)$ similar to $\mathrm{Ti}^{4+}$ and $\mathrm{Zr}^{4+}$. It may thus be that lead on the $\mathrm{B}^{-}$site is allowed in thermodynamic equilibrium at some region in the phase diagram depending on $\mathrm{PbO}$ and $\mathrm{O}_{2}$ partial pressures, and on temperature.

\section{Experimental}

All samples were deposited by a dynamic, reactive magnetron sputtering method using three sources with metallic targets of $\mathrm{Ti}, \mathrm{Zr}$, and $\mathrm{Pb}$, a technique that first has been applied by Bruchhaus et al. [12]. The film were crystallized in-situ at the growth temperature of 550 to $600^{\circ} \mathrm{C}$. Two types of equipments and substrates were used. Thermally oxidized silicon wafers were coated in a NORDIKO 2000 system in the dynamic mode, i.e., the heated wafers rotated on top of the three constantly operating circular magnetron sources. Optical fibers were coated in a self-built tool having three rectangular magnetrons directed towards the center of the cylindrical chamber where the fibers were rotating around their long axes. Details about the processes have been published earlier [8, 13, 14]. In both cases, platinum bottom electrodes were used.

The films were analyzed by standard X-ray diffraction techniques. The $\theta-2 \theta$ diffraction geometry was applied in case of thin films. The films on fibers have been investigated by means of the Debye-Scherrer method. All films have been analyzed in a $\mu$-probe apparatus. A calibration with PZT ceramics of known composition was performed. Some of the thin films 
have been investigated in a transmission electron microscope (TEM) equipped with an electron dispersive spectrometry (EDS) tool. Rutherford backscattering (RBS) was carried out at the facilities of the "Centre d'applications de faisceaux ioniques" at Le Locle, (Switzerland). Synchrotron radiation diffraction was performed at the US National Synchrotron Source at Brookhaven National Laboratory.
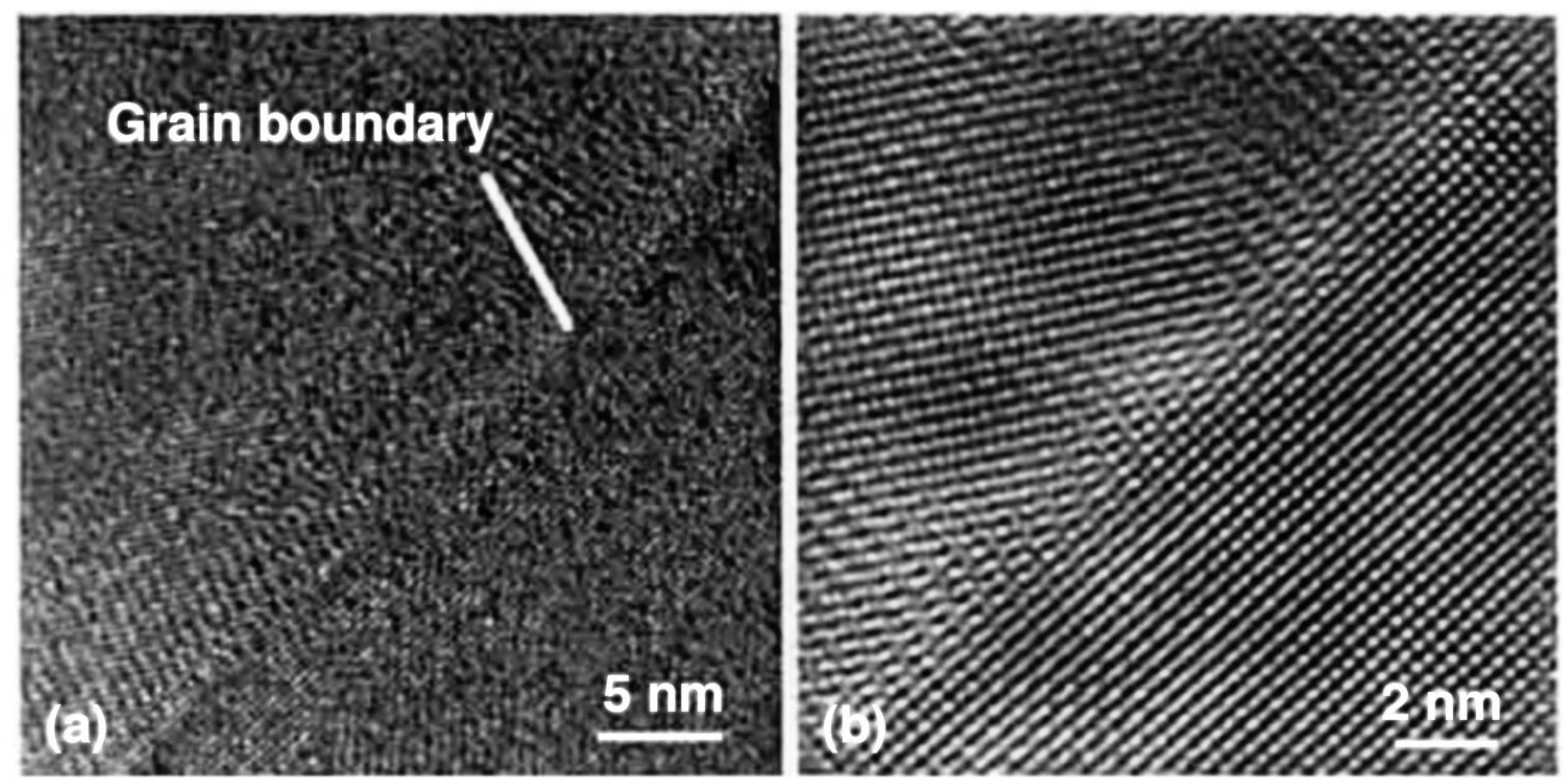

Figure 1. High resolution TEM image of PZT film containing an excess of lead. (a) normal image ; (b) enlarged and filtered image.

\section{Results}

One special sample has been analyzed by p-probe, EDS and RBS in order to exclude systematic errors of chemical concentration measurements. For this purpose, a nominal PZT 45/55 film was deposited on a polished $\mathrm{Al}_{2} \mathrm{O}_{3}$ ceramic platelet. No bottom electrode was used to avoid superposition of RBS peaks. The result of the test is given in table 2 .

The different measurements agree within $+/-2 \%$ for $\mathrm{Zr}(0.44 \pm 0.01)$ and $\mathrm{Ti}(0.56 \pm 0.01)$. All three techniques yielded a PZT concentration that was $30 \%$ or more larger than expected for perovskite PZT. There is a very good agreement between $\mu$-probe analysis and RBS. EDS indicates $5 \%$ more of lead. This value was obtained from the interior of the film. No variation was observed across grain boundaries. The latter were very dense as shown by the high resolution TEM image of figure 1. There was no sign of a second phase or amorphous grain boundaries. Given that the searched second phase should occupy roughly $20 \%$ of the volume, one can conclude that such a second phase does not exist.

\begin{tabular}{|l|l|l|l|c|}
\hline Technique & {$[\mathrm{Pb}]$} & {$[\mathrm{Ti}]$} & {$[\mathrm{Zr}]$} & {$[\mathrm{O}]$} \\
\hline EDS & 1.38 & 0.45 & 0.55 & - \\
\hline$\mu$-probe & 1.30 & 0.43 & 0.57 & 3.28 \\
\hline RBS & 1.32 & 0.45 & 0.55 & 3.57 \\
\hline
\end{tabular}

Table 2. Results of comparative concentration measurements at a nominal PZT45/55 film on alumina, where $[\mathrm{Zr}]+[\mathrm{Ti}]$ was set equal to 1 . 
The oxygen concentration allows the derivation of valence of the excess lead ion. The concentrations given in table 1 can be used to calculate the composition of the excess lead oxide as follows :

$$
\mathrm{Pb}_{1+y} \mathrm{Zr}_{x} \mathrm{Ti}_{1-x} \mathrm{O}_{z}=\mathrm{Pb}_{1}\left(\mathrm{Zr}_{x} \mathrm{Ti}_{1-x}\right) \mathrm{O}_{3}+\mathrm{Pb}_{y} \mathrm{O}_{z-3}
$$

The lead valence is obtained as $2(z-3) / y$ and obtained as 1.9 ( $\mu$ probe) and 3.6 (RBS). The average of 12 more $\mu$-probe measurements at PZT films on platinized silicon wafers yielded an average of 3.4 (see fig. 2). This suggests very much that the excess lead is present in the form of $\mathrm{Pb}^{2+} \mathrm{Pb}^{4+} \mathrm{O}_{3}$, thus as a perovskite diluted in ordinary $\mathrm{PZT}$, and not as $\mathrm{PbO}$, as would be the case if excess lead would be interpreted as missing B-site ions. The proposed chemical formula becomes thus :

$$
\begin{aligned}
& \mathrm{Pb}_{1+y}\left(\mathrm{Zr}_{x} \mathrm{Ti}_{1-x}\right) \mathrm{O}_{z}=\mathrm{Pb}_{1+y / 2}\left(\mathrm{~Pb}_{y / 2} \mathrm{Zr}_{x} \mathrm{Ti}_{1-x}\right) \mathrm{O}_{z} \\
& ->\mathrm{Pb}_{1}\left(\mathrm{~Pb}_{y / 2 / \eta} \mathrm{Zr}_{x / \eta} \mathrm{Ti}_{(1-x) / \eta}\right) \mathrm{O}_{z / \eta}, \eta=1+y / 2
\end{aligned}
$$

As in the case of $\mathrm{PbSc}_{1 / 2} \mathrm{Ta}_{1 / 2} \mathrm{O}_{3}$ [10], a very good correlation between lead excess and lattice constants was observed. The unit cell volume of the perovskite depends quite linearly on the radius of the $\mathrm{B}$ - ion if the A-ion is kept the same. Whatmore and coworkers derived this linear function from all available types of lead perovskite. In this work, we consider only the single crystal data given by Eremkin and coworkers [15] for a wide range of PZT compositions. The linear relation between average $\mathrm{B}$-ion radius (using the radii given in table 1) and the average lattice constant $V^{1 / 3}$ is obtained as (in $\AA$, optimal fit with $\mathrm{R}=0.9989$ ) :

$$
V^{1 / 3}=2.740+1.662 \cdot r_{\mathrm{B}}
$$

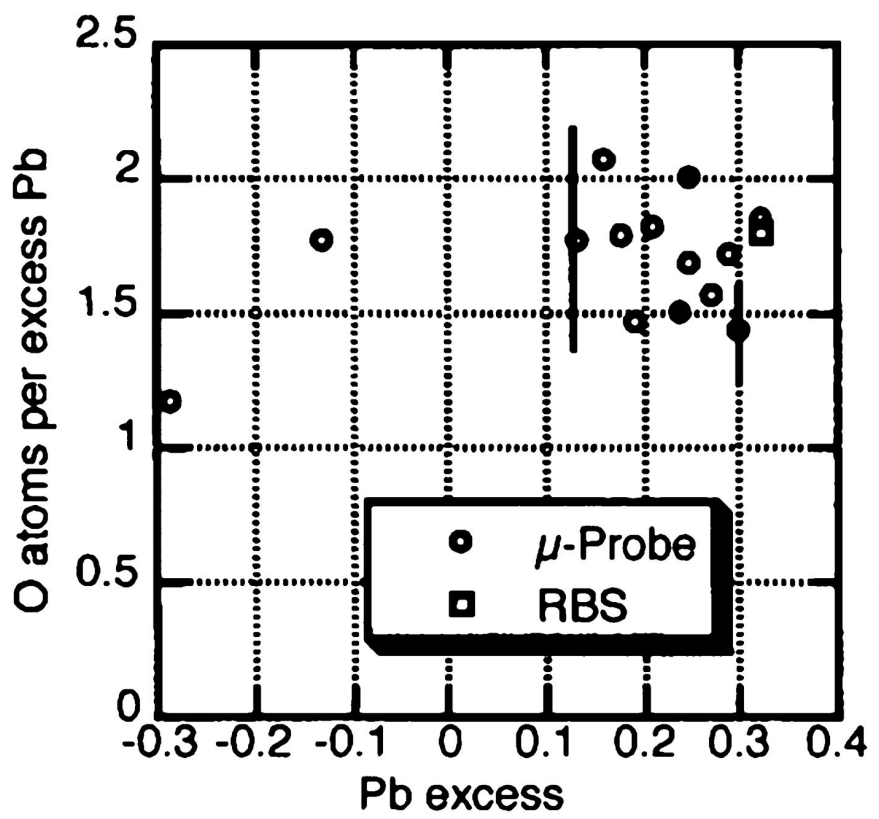

Figure 2. Number of oxygen atoms per excess lead atom. RBS : PZT45155 on alumina ; $\mu$-probe : PZT 40/60 on platinized silicon wafers. Errors bars refer to $\pm 1 \%$ error in $[\mathrm{Pb}]$ and $[\mathrm{O}]$ determination. 
In order to test the correlation with lead excess, a series of nominal PZT40/60, \{100)-textured films covering 5 different lead oxide fluxes and three different deposition temperatures was prepared on silicon wafers. Figure 3 shows the measured lattice constant $a$ as obtained by $\theta-2 \theta$ XRD with respect to the applied lead oxide flux. It is indeed seen that $a$ increases with increasing lead oxide flux. From the composition obtained by p-probe analysis the mean ionic radius on site $\mathrm{B}$ was calculated including $\left[\mathrm{Pb}^{4+}\right]$ according to eqn 2 , using the ion radii given in table 1. The result is shown in fig. 3 together with the linear relation of eqn 3 . There is a very good coincidence between the theoretical and the experimental data. There is even an explanation for the somewhat lower experimental values. The (small) tetragonal splitting was not taken into account, as the $(00 n)$-peaks could not really be separated from the $(n 00)$ peaks $(n=1,2)$ for most of the films. The tetragonal splitting was only observed at the films with the smallest lead excess. Of course, an increase in the out-of plane lattice constant may also be caused by an in-plane film stress. X-ray peak shifts may also arise from film stresses. However, the PZT thin films stress is at least 10 times smaller than would be needed to explain the large shift. The theoretical curve fits also well to $V^{1 / 3}$ evaluated by the DebyeScherrer method (see fig. 3) from PZT thin films on fibers. The good correlation between lattice size and $\mathrm{B}$-site radius for the $\mathrm{Pb}_{\mathrm{B}}{ }^{4+}$ model speaks very much against a B-site vacancy model, which should rather show a shrinking lattice.

\section{Lattice parameter vs. mean ion radius on B-site}

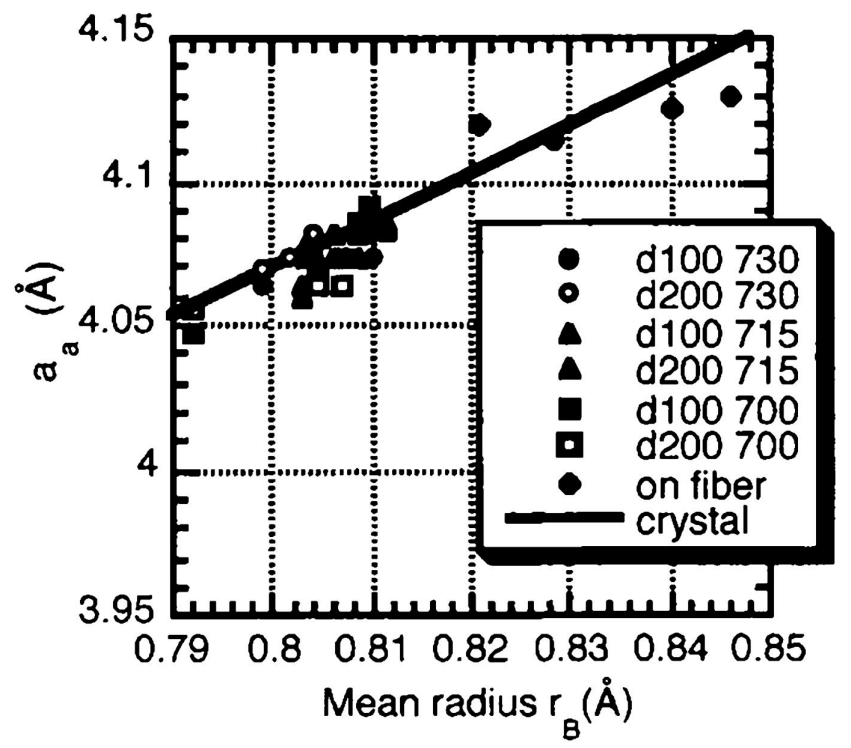

Figure 3. Unit cell parameter of PZT40/60 films on silicon wafers (from $d_{100}, d_{200}$ reflections) and PZT $42 / 58,50 / 50,53 / 47,61 / 39$ on fibers as a function of the mean ionic radius on the B- site. Eqn 3 is inserted as solid line.

If lead goes also to the B-site of the perovskite, the structure factors in X-ray diffraction should be modified accordingly. Synchrotron radiation was used to address this question. A $1.2 \mu \mathrm{m}$ thick PZT45/55 film with $22 \%$ lead excess was prepared for this purpose. The chosen wavelengths of 0.9528 and $0.9753 \AA$ are near the absorption edge due to ionization of $\mathrm{Pb}^{2+}$, yielding a large variation of the scattering factor of the A-site $\mathrm{Pb}$. The measured intensity ratio of the Bragg peak (200) with respect to the Bragg peak (100) amounts to 14.1 and 12.7 for the two respective wavelengths. The intensities have been calculated for three solutions, yielding 10.7/8.4 for the perovskite with lead exclusively on the B-site, 15.1/11.7 for the 
excess lead half on B-site and half on A-site, and 10.3/8.2 for a model putting the excess lead on interstitial sites between two A-sites $((1 / 2,0,0),(0,1 / 2,0),(0,0,1 / 2))$. Clearly, the B-site model fits best the experimental data.

A further evidence arises from the property shift observed in excess lead material. Properties of PZT change very much with the compositional parameter $x=[\mathrm{Zr}] /([\mathrm{Zr}]+[\mathrm{Ti}])$. As the mean radius $\left\langle r_{\mathrm{B}}\right\rangle$ of the $\mathrm{B}$-cation increases linearly with $x$, one may also say that the properties change with $\left\langle r_{\mathrm{B}}\right\rangle$. Lead on the B-site would thus shift the properties as if the $x$ would be increased. This is indeed observed. The PZT 40/60 series, being close to morphotropic boundary 52/48, shows an increasing dielectric constant with increasing lead excess, as if the concentration of $\mathrm{Zr}$ would be enlarged (see fig 4). The best coincidence with ceramics data is achieved when $\mathrm{Pb}_{\mathrm{B}}$ is counted as $\mathrm{Zr}$ ion, i.e., for equivalent properties, the compositional parameter $x$ has to be replaced by $x^{\prime}=\left([\mathrm{Zr}]+\left[P b_{\mathrm{B}}\right]\right) /\left([\mathrm{Zr}]+\left[P b_{\mathrm{B}}\right]+[T i]\right)$. This was as well seen for PZT films on fibers, which had properties like rhombohedra1PZT ( $\mathrm{Zr}$ rich), although they are richer in Ti than $\mathrm{Zr}$ (see fig. 5).

In-situ sputter deposition appears to be especially prone to the incorporation of $\mathrm{Pb}^{4+}$ into the perovskite. Obviously, $\mathrm{PbO}_{2}$ is created during the process and incorporated into the perovskite lattice. It turned out that our sputter process was able to deposit $\mathrm{PbO}_{1.6}$ up to temperatures of $490^{\circ} \mathrm{C}$, whereas at normal atmosphere this composition decays to $\mathrm{PbO}_{1.33}$ already near $400^{\circ} \mathrm{C}$, and to $\mathrm{PbO}$ at $480^{\circ} \mathrm{C}$ [17]. This means that the used sputter conditions are much more oxidizing than the 0.2 bar of oxygen that usually are applied during PZT anneals. Most probably, $\mathrm{PbO}_{2}$ is created on the surface by reaction with atomic oxygen or impinging negatively charged oxygen. The relatively low deposition temperature may also inhibit the necessary diffusion in the first sub-layers to allow exchange of $\mathrm{Pb}_{\mathrm{B}}$ by $\mathrm{Zr}$ or Ti.

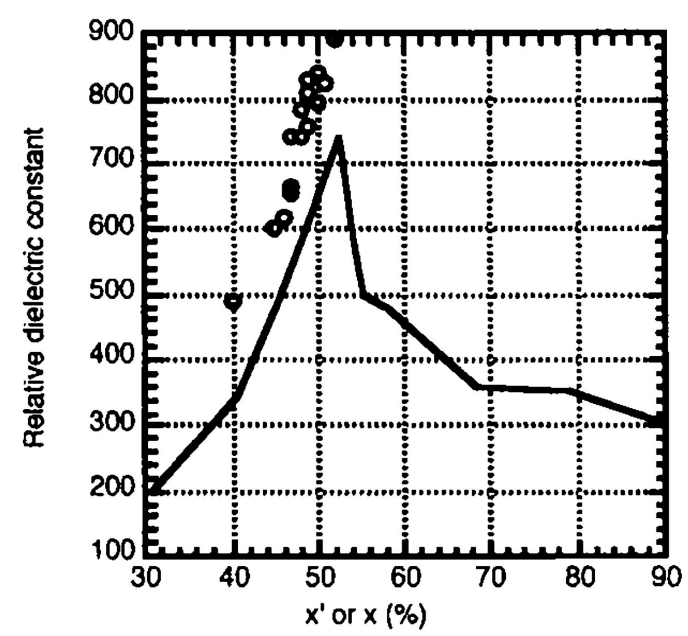

Figure 4. Relative dielectric constant of nominal PZT40/60 films on platinized silicon wafers exhibiting various amounts of lead excess (circles). The corrected compositional parameter $x^{\prime}$ has been used. Reference values for bulk ceramics are given by the solid line as a function of $x$ [16].

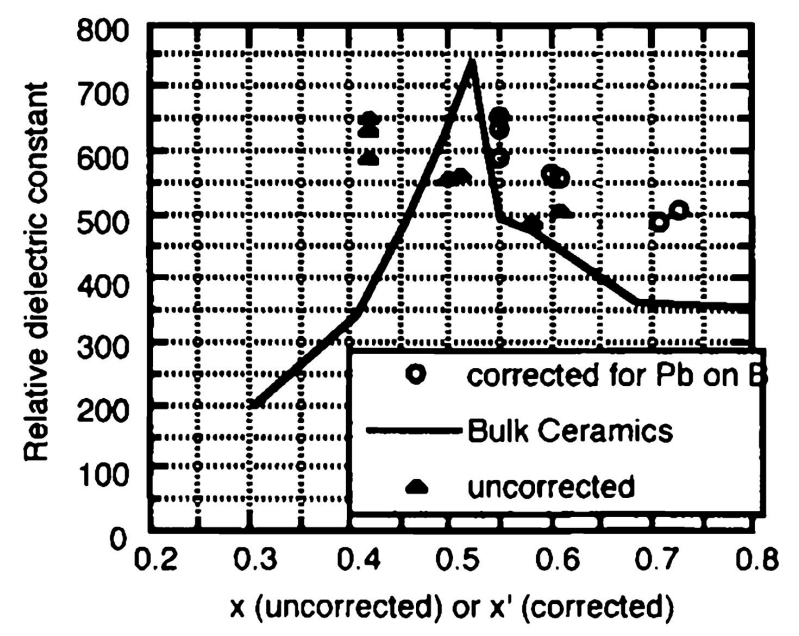

Figure 5. Relative dielectric constant of nominal PZT films on fibers. 


\section{Conclusions}

The paper has given ample evidence that lead excess as incorporated in perovskite PZT during in-situ sputter deposition is partially occupying as a 4-valent ion the B-site of the lattice. The PZT system in this case has to be understood as a solid solution of $\mathrm{PbZrO}_{3}$, $\mathrm{PbTiO}_{3}$ and $\mathrm{PbPbO}_{3}$. The properties are shifting in the same direction as if the $\mathrm{Zr}$ content would be increased by the amount of lead on the B-site.

\section{Acknowledgements}

This work was supported by the Swiss Federal Office for Education and Science (European project MEDCOM), and the Board of the Swiss Federal Institutes of Technology through the Priority Programs on Materials Science and Optics.

\section{References}

1. Malic, B., et al., Integrated Ferroelectrics, 2001. 30: p. 81-89.

2. Sato, E., et al., Appl. Phys. Lett., 1994.65: p. 2678-80.

3. Foster, C.M., et al., J.Appl. Phys., 1997.81: p. 2349-2357.

4. Keijser, M.d. and G.J.M. Dormans, J.Cryst. Growth, 1995. 123: p. 537-544.

5. Shannon and Previtt, Acta Cryst. A, 1976.32: p. 75.

6. Maeder, T. and P. Muralt, MRS Symp. Proc., 1994.341: p. 361- 366.

7. Tabata, H., et al., Jpn. J. Appl. Phys., 1992.31: p. 2968-2970.

8. Muller, C.A.P., P. Muralt, and D.M. Costantini, Ferroelectrics, 1999.225: p. 133-140.

9. Costantini, D.M., et al., Appl. Phys. Lett., 2001.

10. Whatmore, R.W., Z. Huang, and M. Todd, J. Appl. Phys., 1997. 82: p. 5686-94.

11. Kleber, W., Einführung in die Kristallographie. 15 ed. 1983: VEB Verlag Technik Berlin.

12. Bruchhaus, R., et al., Integrated Ferroelectrics, 1992. 2: p. 157- 164.

13. Hiboux, S., P. Muralt, and T. Maeder, J. Mat. Res., 1999. 14: p. $4307-4318$.

14. Muller, C.A.P. and G.R. Fox, J.Phys. IV, 1998.8: p. Pr9-17.

15. Eremkin, V.V., V.G. Smotrakov, and E.G. Fesenko, Ferroelectrics, 1990.110:p. 137-144.

16. Jaffe, B., W.R. Cook, and H. Jaffe, Piezoelectric Ceramics. 1971, London: Academic Press.

17. Brown, H.E., ed. Lead oxide:properties and applications. 1985, Int. Lead Zinc Res. Organization: New York. 